\title{
Teknik perbanyakan massal parasitoid Anagrus nilaparvatae (Pang et Wang) (Hymenoptera: Mymaridae) dengan kotak plastik
}

\author{
Mass-rearing technique of Anagrus nilaparvatae (Pang et Wang) \\ (Hymenoptera: Mymaridae) using plastic box \\ Araz Meilin ${ }^{1 *}$, Y. Andi Trisyono ${ }^{2}$, Edhi Martono², \\ Damayanti Buchori ${ }^{3}$ \\ ${ }^{1}$ Balai Pengkajian Teknologi Pertanian (BPTP) Jambi \\ Jalan Samarinda Paal Lima, Kota Baru, Jambi 36128 \\ ${ }^{2}$ Jurusan Hama dan Penyakit Tumbuhan, Fakultas Pertanian, Universitas Gadjah Mada, \\ Jalan Flora No.1 Bulak Sumur, Yogyakarta 55281 \\ ${ }^{3}$ Departemen Proteksi Tanaman, Fakultas Pertanian, Institut Pertanian Bogor \\ Jalan Kamper, Kampus Darmaga IPB, Bogor 16680
}

(diterima Februari 2012, disetujui Maret 2012)

\begin{abstract}
ABSTRAK
Parasitoid Anagrus nilaparvatae (Pang et Wang) merupakan salah satu parasitoid telur dari hama wereng batang padi cokelat (Nilaparvata lugens Stål). Penelitian ini bertujuan untuk mengembangkan teknik perbanyakan A. nilaparvatae dengan kotak plastik berukuran $14 \mathrm{~cm}$ x 18,5 $\mathrm{cm} \times 18,5 \mathrm{~cm}$ yang terbuat dari plastik mika dengan satu sisi bagian atasnya diberi tabung reaksi (panjang $10 \mathrm{~cm}$ ), ditempatkan diatas baki berisi persemaian padi yang mengandung sekitar 11.130 telur $N$. lugens. Satu kotak plastik yang diinfestasi dengan 50 imago parasitoid menghasilkan 355 imago parasitoid. Jumlah produksi parasitoid menurun menjadi 164 imago jika diinfestasi dengan 100 imago parasitoid. Pemunculan parasitoid dimulai dari sebelum pukul 07:00 sampai 16:00 WIB dengan laju tertinggi $(36,2 \%)$ pada pukul 10:00 WIB. Biaya untuk membuat satu kotak plastik hanya Rp10.000,- dan perkiraan biaya untuk memproduksi satu parasitoid adalah Rp60,-. Hasil penelitian ini menunjukkan kotak plastik merupakan teknik yang sederhana dan murah untuk perbanyakan massal parasitoid A. nilaparvatae.
\end{abstract}

Kata kunci: parasitoid telur, Nilaparvata lugens, wereng coklat

\begin{abstract}
Anagrus nilaparvatae (Pang et Wang) is an egg-parasitoid of rice brown planthopper (Nilaparvata lugens Stål). The objective of this study was to develop a mass-rearing technique of A. nilaparvatae. Mass-rearing was done using a plastic box $(14 \mathrm{~cm} \times 18.5 \mathrm{~cm} \times 18.5 \mathrm{~cm}$, made of plastic-mica, the upper side equipped with a $10 \mathrm{~cm}$ test tube), placed on a tray with rice seedlings containing an estimated of 11,130 eggs of $N$. lugens. About 355 adult parasitoids were successfully released per box when each box was infested with 50 parasitoids. The number of parasitoids produced were reduced to 164 adults when the infestation was made at 100 parasitoids per box. The emergence of parasitoids started around 07:00 am until 04:00 pm with the highest rate (36.2\%) occured at 10:00 am. One plastic box cost only Rp10.000,-; thus the estimate cost to produce one parasitoid using this tecnique was Rp60,- These findings suggest that the plastik box is a simple and inexpensive technique for mass-rearing of $A$. nilaparvatae.
\end{abstract}

Key words: egg-parasitoid, Nilaparvata lugens, brown planthopper

\footnotetext{
*Penulis korespondensi: Araz Meilin. Balai Pengkajian Teknologi Pertanian (BPTP) Jambi, 


\section{PENDAHULUAN}

Pengendalian hayati dalam skala luas memerlukan jumlah agens hayati yang banyak sehingga perlu usaha pembiakan massal. Pembiakan massal dilakukan untuk mengembangbiakkan agens hayati dengan menggunakan media alami maupun media buatan dalam habitat atau lingkungan yang dibentuk sesuai lingkungan aslinya sehingga diperoleh sejumlah tertentu sesuai kebutuhan (Untung 2006). Apabila perbanyakan massal parasitoid di laboratorium telah berhasil, diharapkan semua penelitian yang berhubungan dengan serangga tersebut dapat dilaksanakan dengan mudah. Kemungkinan lain yang lebih luas adalah pelepasan parasitoid di lapangan untuk membantu pengendalian (Laba et al. 1999). Perbanyakan massal juga dapat ditujukan untuk menyediakan musuh alami atau agens hayati siap pakai agar petani mudah memperoleh dan mengaplikasikannya (Kartohardjono 2011).

Parasitoid Anagrus sp. adalah parasitoid telur wereng batang padi cokelat (Nilaparvata lugens Stål.) yang potensinya dalam menekan $N$. lugens telah banyak diketahui. Parasitasi Anagrus sp. pada telur $N$. lugens berkisar dari 15,7-35,7\% dengan rata-rata $24,9 \%$ (Yaherwandi \& Syam 2007), sedangkan Maryana (1994) melaporkan 11,31\%. Kemampuan parasitasi Anagrus dapat mencapai $38,21 \%$ pada pertanaman padi dan $64,09 \%$ terhadap $N$. lugens yang berada pada rumputan (Atmadja \& Arifin 1990).

Perbanyakan massal adalah hal yang paling penting dalam pengendalian hayati baik melalui introduksi (pengendalian hayati klasik), konservasi (pengendalian hayati alami) dan multiplikasi (pengendalian hayati terapan) (Parra 2010). Metode perbanyakan parasitoid Anagrus sp. di Indonesia sebelumnya telah diinformasikan oleh Atmaja (1997) dan Yaherwandi \& Syam (2007) dengan menggunakan tanaman padi berumur satu bulan dan tidak ada informasi cara panen parasitoid tersebut.

Penelitian ini bertujuan untuk mengembangkan teknik perbanyakan massal parasitoid Anagrus nilaparvatae yang murah dan mudah, dengan menggunakan kotak plastik dan tabung yang menempel pada kotak sebagai alat untuk memanen parasitoid dewasa, dan bibit padi umur 1 minggu yang telah mengandung telur $N$. lugens.

\section{BAHAN DAN METODE}

\section{Lokasi dan waktu penelitian}

Penelitian dilaksanakan di Laboratorium Toksikologi Pestisida dan rumah kaca, Jurusan Hama dan Penyakit Tumbuhan, Fakultas Pertanian, Universitas Gadjah Mada, Yogyakarta. Suhu ruangan di laboratorium berkisar antara $27-31{ }^{\circ} \mathrm{C}$ dengan kelembaban $64-84 \%$. Penelitian dilaksanakan selama bulan Juli-November 2011.

\section{Penyediaan bibit padi}

Tanaman padi yang digunakan adalah varietas Cisadane yang rentan terhadap $N$. lugens. Benih padi direndam dalam air selama 24 jam, kemudian dicuci dengan air dan dikeringanginkan selama 24 jam. Benih padi $( \pm 20 \mathrm{~g})$ disebar dalam baki plastik ( $15 \mathrm{~cm} \times 20 \mathrm{~cm} \times 3 \mathrm{~cm})$ yang telah berisi tanah dengan ketebalan $1 \mathrm{~cm}$. Bibit padi umur 7 hari yang digunakan untuk perbanyakan parasitoid sudah mengandung telur N. lugens.

\section{Penyediaan $N$. lugens dan parasitoid}

Populasi $N$. lugens dibiakkan dengan bibit padi menggunakan metode sama seperti yang sudah digunakan di Laboratorium Toksikologi Pestisida sejak tahun 1985. Parasitoid telur diambil dari lapangan dengan cara pemerangkapan (Trisyono 1991; Maryana 1994; Yaherwandi \& Syam 2007) dengan perubahan pada jarak peletakan pot perangkap dan varietas yang digunakan. Jarak antar pot peletakan adalah 30 meter dan varietas Cisadane. Tanaman padi umur satu bulan dalam pot plastik hitam (diameter atas $18 \mathrm{~cm}$, diameter bawah $12 \mathrm{~cm}$, tinggi $14 \mathrm{~cm}$ ) diinfestasi dengan 10 betina $N$. lugens yang siap bertelur selama dua hari, selanjutnya ditempatkan pada pertanaman padi di sawah yang merupakan lokasi serangan $N$. lugens. Tanaman dalam pot tersebut dibiarkan selama dua hari agar parasitoid meletakkan telur pada telur $N$. lugens. Pot kemudian diambil dan dibawa ke rumah kaca dan tanaman padi dipindahkan ke pot berdiameter $8 \mathrm{~cm}$, dipotong setinggi $18 \mathrm{~cm}$, dan dikurung dengan kurungan plastik (diameter $6 \mathrm{~cm}$, 


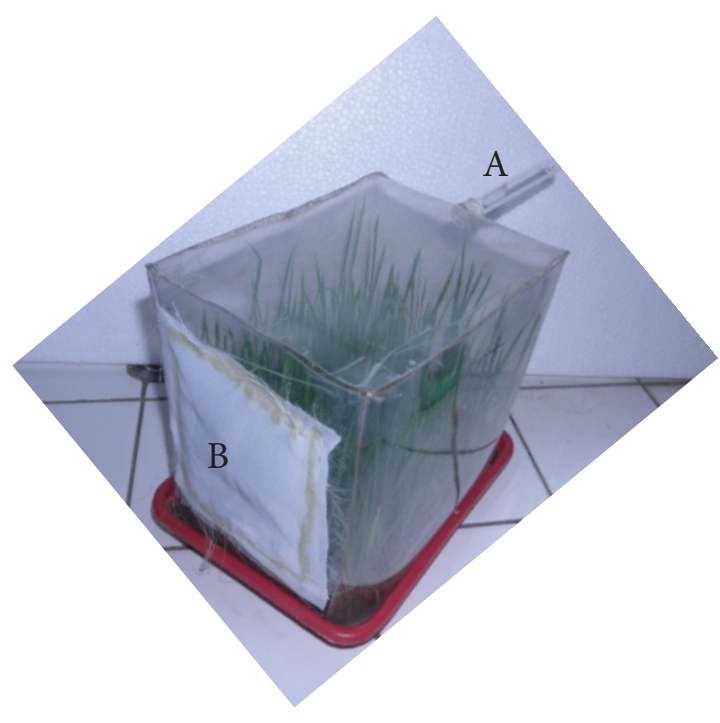

Gambar 1. Kotak 'plastik' (ukuran $14 \mathrm{~cm}$ x 18,5 cm x $18,5 \mathrm{~cm}$ ) yang terbuat dari plastik mika (tebal 0,6 mm) dan bibit padi Cisadane berumur 1 minggu dalam baki plastik. A: tabung reaksi (diameter $1 \mathrm{~cm}$, panjang $10 \mathrm{~cm}$ ) untuk panen parasitoid; B: kain kasa (ukuran $6 \mathrm{~cm} \times 10 \mathrm{~cm}$ ) untuk aerasi

tinggi $20 \mathrm{~cm}$ ). Bagian atas kurungan diberi kain kasa halus, selanjutnya tanaman ini dibawa ke laboratorium ditunggu sampai parasitoid muncul.

Parasitoid yang muncul dipelihara dalam kotak plastik. Kotak plastik adalah kurungan yang memiliki ukuran $14 \mathrm{~cm} \times 18,5 \mathrm{~cm} \times 18,5 \mathrm{~cm}$, yang terbuat dari plastik mika (tebal $0,6 \mathrm{~mm}$ ) dengan sisi depan bagian tengah atas diberi tabung reaksi (panjang $10 \mathrm{~cm}$, diameter $1 \mathrm{~cm}$ ). Tabung reaksi berfungsi untuk memudahkan panen parasitoid. Saat panen, tabung reaksi diarahkan ke cahaya dan semua parasitoid yang muncul masuk kedalam tabung reaksi karena parasitoid ini bersifat fototaksis positif. Parasitoid dipanen dengan mengganti tabung reaksi setiap kali panen. Pada sisi lain (berlawanan dengan tabung reaksi) diberi kain kasa $(6 \mathrm{~cm}$ x $10 \mathrm{~cm})$ untuk aerasi kotak plastik (Gambar 1).

\section{Perbanyakan massal}

\section{Produksi massal parasitoid}

Percobaan terdiri atas dua perlakuan yaitu infestasi dengan kepadatan 50 dan 100 individu parasitoid. Masing-masing perlakuan mempunyai tiga ulangan. Seratus imago N. lugens siap bertelur diinfestasikan pada bibit padi umur satu minggu dalam baki plastik ukuran $15 \mathrm{~cm} \times 20 \mathrm{~cm} \times 3 \mathrm{~cm}$ dan ditutup dengan kotak plastik. $N$. lugens dibiarkan dalam kotak sampai semua mati. Berdasarkan hasil penelitian sebelumnya (Ratna 2011), prediksi jumlah telur $N$. lugens yang diletakkan adalah 11.130 butir per kotak. Satu hari kemudian, ke dalam masing-masing kotak plastik diinfestasikan 50 dan 100 parasitoid sesuai perlakuan. Pada setiap dinding kotak plastik dioleskan madu. Pengamatan dilakukan terhadap jumlah parasitoid yang muncul per hari. Pemunculan parasitoid pertama terjadi pada hari ke-9 dan pemunculan terakhir pada hari ke-13 setelah infestasi.

\section{Laju pemunculan parasitoid}

Laju pemunculan parasitoid diamati dengan menghitung jumlah parasitoid yang muncul setiap jam mulai dari jam 07:00 sampai 16:00 WIB dalam satu hari. Pengamatan hanya dilakukan pada kotak plastik yang diinfestasi 50 individu parasitoid. Laju pemunculan parasitoid (\%) dihitung dengan membagi jumlah parasitoid yang muncul per satu jam dengan total parasitoid yang muncul dalam satu hari.

\section{Nisbah kelamin keturunan}

Nisbah kelamin $(\%)$ keturunan $\left(\mathrm{F}_{1}\right)$ dihitung dengan membagi jumlah parasitoid betina dengan total parasitoid yang muncul dari kotak plastik dengan infestasi 50 parasitoid.

\section{Biaya perbanyakan massal parasitoid}

Biaya perbanyakan massal parasitoid dengan kotak plastik dihitung berdasarkan biaya alat dan bahan yang digunakan dalam perbanyakan massal tersebut, serta biaya upah pekerjaan perbanyakan inang dan parasitoidnya. Biaya alat dan bahan didasarkan pada harga riil yang dikeluarkan saat membeli, sedangkan biaya upah didasarkan Peraturan Menteri Keuangan No. 100/PMK02/2010 tentang Standar Biaya Umum (SBU) Tahun Anggaran 2011 yang disetarakan dengan biaya pembantu peneliti. Upah pembantu peneliti untuk 1 jam adalah Rp20.000,-

\section{HASIL}

\section{Produksi parasitoid}

Parasitoid A. nilaparvatae mulai muncul dari kotak plastik pada hari ke-9 setelah infestasi dan berakhir pada hari ke-13. Rata-rata jumlah 
parasitoid yang muncul pada setiap kotak plastik yang diinfestasi dengan 50 parasitoid adalah 355 individu, sedangkan pada kotak plastik yang diinfestasi dengan 100 parasitoid jumlah keturunan lebih rendah yaitu 164 individu. Jumlah parasitoid muncul terbanyak pada hari ke-9 setelah infestasi dan jumlah pemunculan terus menurun (Gambar 2).

\section{Laju pemunculan parasitoid}

Parasitoid A. nilaparvatae muncul setiap hari dari jam 07:00 sampai 16:00 WIB. Jumlah parasitoid yang muncul pada pagi hari (pukul 07:00 WIB) masih sedikit dan laju pemunculan meningkat sampai mencapai puncaknya pada pukul 10:00 WIB. Selanjutnya, laju pemunculan terus menurun sampai pukul 16:00 WIB (Gambar $3)$.

\section{Nisbah kelamin keturunan}

Keturunan parasitoid A. nilaparvatae yang dihasilkan dari kotak plastik didominasi oleh betina mulai dari $95-100 \%$, dengan rata-rata $97,2 \%$ betina.

\section{Biaya perbanyakan massal parasitoid}

Biaya upah yang digunakan adalah biaya upah pembantu peneliti dalam pekerjaan perbanyakan inang dan parasitoid selama 1 jam (60 menit). Total waktu yang dibutuhkan untuk perbanyakan

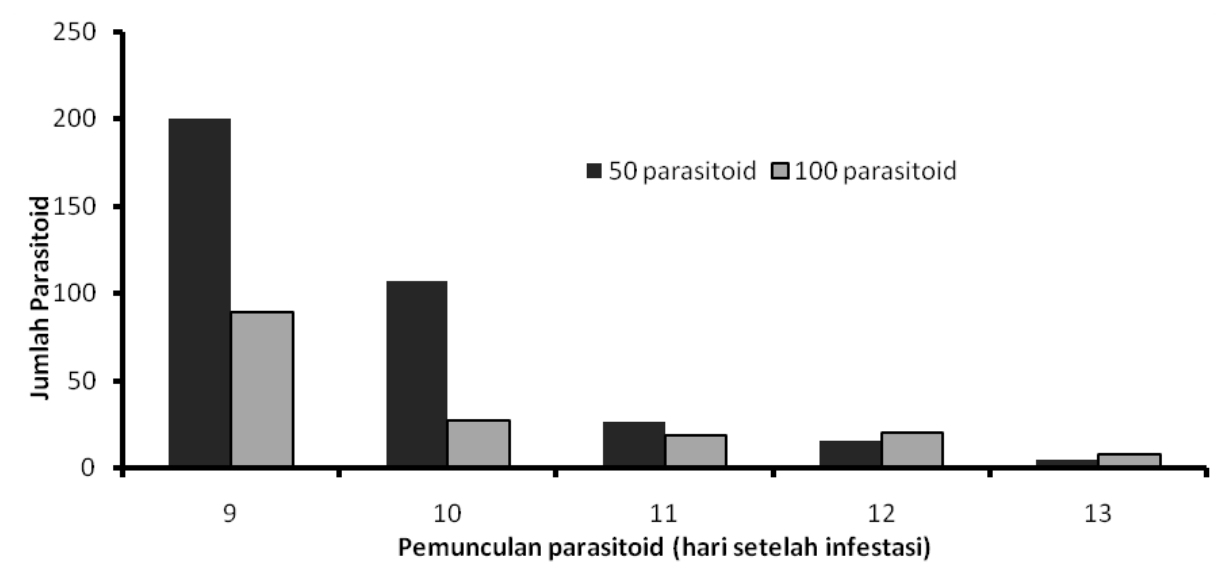

Gambar 2. Jumlah keturunan parasitoid Anagrus sp. yang muncul per hari dari kotak plastik yang diinfestasi dengan 50 dan 100 imago parasitoid. Setiap kotak plastik diinfestasi dengan 100 gravid Nilaparvata lugens dan diestimasi akan menghasilkan 11.130 telur. Imago parasitoid diinfestasikan satu hari setelah infestasi gravid Nilaparvata lugens

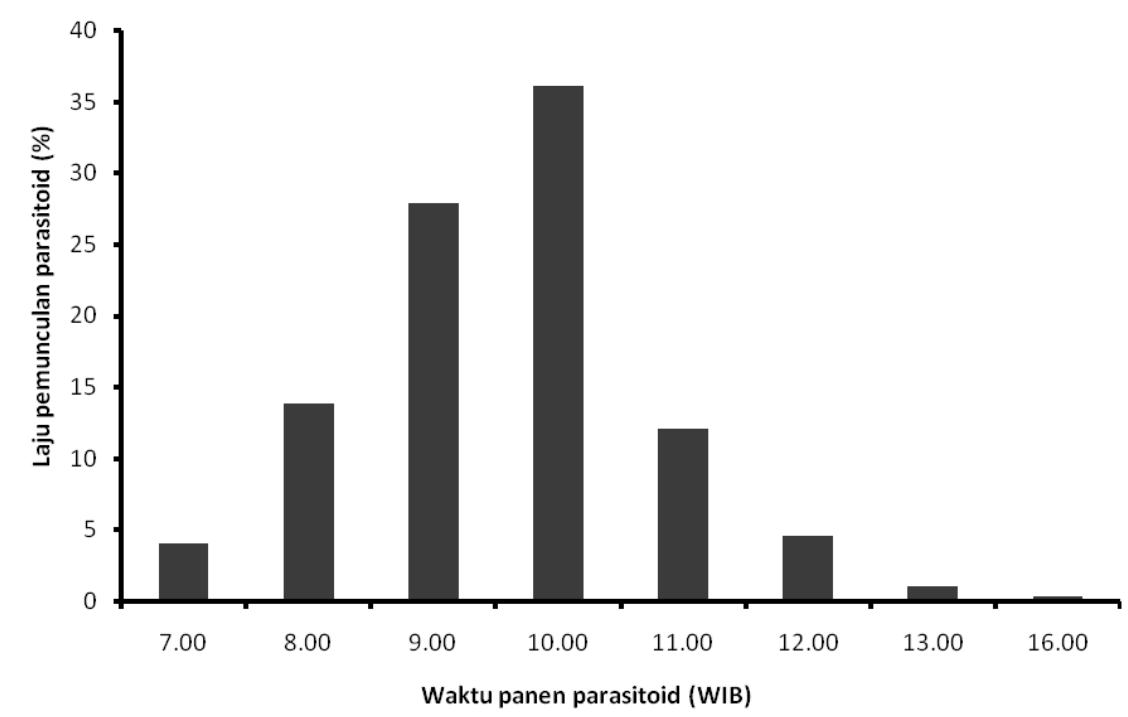

Gambar 3. Laju pemunculan keturunan parasitoid Anagrus sp. pada setiap jam panen dari kotak plastik yang diinfestasi dengan 100 gravid Nilaparvata lugens dan 50 parasitoid Anagrus sp. Nilaparvata lugens diinfestasikan satu hari sebelum infestasi parasitoid Anagrus sp. 
Tabel 1. Biaya perbanyakan massal parasitoid Anagrus nilaparvatae per satu kotak plastik

\begin{tabular}{lc}
\hline Komponen biaya & Biaya per generasi (Rp) \\
\hline Benih padi & 200 \\
- Satu stoples $(20 \mathrm{~g})$ & 200 \\
- Satu baki $(20 \mathrm{~g})$ & 525 \\
Biaya penyusutan stoples* & 500 \\
Biaya penyusutan kotak plastik** & 20.000 \\
Upah (total waktu 60 menit untuk perbanyakan inang & \\
dan parasitoid) & 21.425 \\
Total biaya & 60 \\
Biaya produksi satu parasitoid (Rp 21.425/355) & \\
\hline
\end{tabular}

*Harga satu stoples adalah Rp10.500,- dan dapat digunakan untuk 20 generasi.

**Biaya satu kotak plastik adalah Rp10.000,- dan dapat digunakan untuk 20 generasi.

inang adalah 36 menit (rendam benih $=2$ menit, mengering-anginkan benih $=2$ menit, menabur benih ke stoples $=2$ menit, infestasi inang $=$ 15 menit, mengganti pakan 3 kali 5 menit $=15$ menit), sedangkan waktu untuk perbanyakan parasitoid adalah 24 menit (persiapan dan menabur benih ke baki $=3$ menit, menyiram bibit $4 \times 1$ menit $=4$ menit, infestasi parasitoid $=15$ menit dan panen parasitoid $=2$ menit). Dengan sudah memperhitungkan biaya penyusutan alat, total biaya yang diperlukan untuk menghasilkan 355 parasitoid A. nilaparvatae. dari satu kotak plastik adalah Rp21.425,- atau Rp60,- per imago (Tabel 1).

\section{PEMBAHASAN}

Satu kotak plastik (ukuran $14 \mathrm{~cm}$ x 18,5 cm x 18,5 $\mathrm{cm}$ ) yang terbuat dari plastik mika (tebal 0,6 mm) dengan bagian depan dan tengah atas diberi tabung reaksi (panjang $10 \mathrm{~cm}$, diameter $1 \mathrm{~cm}$ ) yang diinfestasi dengan 50 parasitoid A. nilaparvatae dapat menghasilkan 355 parasitoid A. nilaparvatae. Hasil ini lebih banyak dari pada hasil penelitian Krugner et al. (2008) yang mendapatkan 219 betina dan 38 jantan dalam perbanyakan massal Anagrus epos pada telur Circulifer tenellus dengan menggunakan satu kurungan akrilik $(10 \mathrm{~cm} \mathrm{x}$ $10 \mathrm{~cm}$ x $15 \mathrm{~cm}$ ). Krugner et al. (2009) berhasil mengembangkan program perbanyakan massal parasitoid $A$. epos di California menggunakan kurungan akrilik. Chandra \& Dick (1988) juga berhasil mengembangkan Anagrus flaveolus Waterhouse dengan kurungan terbuat dari tabung plastik transparan (panjang $160 \mathrm{~mm}$ dan diameter $24 \mathrm{~mm}$ ), bagian ujung atas ditutup, dengan dua atau tiga lubang aerasi disamping kurungan. Chiappini et al. (2004) mengembangkan perbanyakan massal parasitoid Anagrus breviphragma secara in vitro tanpa komponen serangga.

Produksi massal parasitoid A. nilaparvatae dalam kotak plastik yang diinfestasi 100 parasitoid menghasilkan 164 parasitoid. Hasil ini lebih rendah dibanding dengan infestasi 50 parasitoid. Kepadatan inang mempengaruhi produksi parasitoid, karena kemungkinan terjadinya superparasitisme walaupun selalu tersedia inang. Superparasitisme sendiri (self superparasitisme) dapat terjadi jika banyak parasitoid (patch) berada pada tempat yang sama dalam 24 jam (Gauthier et al. 1996). Superparasitisme umumnya menurunkan kebugaran (fitness) parasitoid betina karena hanya satu keturunan yang dapat hidup. Walaupun parasitoid betina dapat membedakan inang terparasit dan tidak terparasit (Gauthier 1996; Darrouzet 2007, 2008; van Lanteren 1978) serta inang berkualitas, namun hal ini tidak selalu berarti bahwa parasitoid dapat menghindari superparasitisme (van Lanteren et al. 1978). Superparasitisme mengurangi besar kecilnya ukuran parasitoid, menjadikan parasitoid betina lebih bugar dibandingkan jantan, dan meningkatkan mortalitas embrio (SantolamazzaCarbone \& Rivera 2003).

Laju pemunculan parasitoid merupakan salah satu karakter biologi parasitoid yang perlu diketahui. Dengan menggunakan kotak plastik laju pemunculan parasitoid A. nilaparvatae per jam mudah diketahui. Laju pemunculan ini menunjukkan bahwa waktu panen parasitoid dalam satu hari dapat dilakukan setelah laju pemunculan maksimal yaitu setelah jam 10:00 WIB. Nisbah kelamin keturunan yang dihasilkan didominasi 
oleh betina sehingga parasitoid $A$. nilaparvatae sangat potensial sebagai agens pengendali biologi untuk mengendalikan $N$. lugens. Disamping itu biaya yang dibutuhkan juga sangat murah, yaitu Rp60,- per imago. Pengembangan teknik perbanyakan massal dengan bahan yang sederhana sangat mungkin untuk diadopsi di tempat lain sehingga sangat mendukung untuk pelaksanaan pelepasan parasitoid A. nilaparvatae hasil biakan laboratorium. Menurut Parra (2010), perbanyakan massal meliputi produksi jutaan serangga untuk mengendalikan serangga hama dalam menunjang Pengendalian Hama Terpadu. Perbanyakan massal juga didefinisikan oleh Chambers (1977) merupakan produksi serangga dalam jumlah ratusan sampai jutaan per minggu. Hasil penelitian ini juga menunjukkan bahwa kotak plastik dapat dijadikan sebagai alat untuk perbanyakan massal parasitoid A. nilaparvatae.

\section{KESIMPULAN}

Kotak plastik berukuran $14 \mathrm{~cm}$ x 18,5 $\mathrm{cm}$ x 18,5 $\mathrm{cm}$, yang terbuat dari plastik mika (tebal 0,6 mm), dan dilengkapi dengan tabung reaksi (panjang $10 \mathrm{~cm}$, diameter $1 \mathrm{~cm}$ ) dapat digunakan untuk perbanyakan massal parasitoid A. nilaparvatae. Infestasi 50 parasitoid dapat menghasilkan 355 keturunan parasitoid dengan biaya Rp60,- per imago. Panen parasitoid A. nilaparvatae maksimal dapat dilakukan setelah pukul 10:00 WIB.

\section{UCAPAN TERIMA KASIH}

Terima kasih disampaikan kepada Dr. Serguei V. Triapitsyn, Entomology Research Museum, Department of Entomology, University of California, Riverside, $C A$ atas identifikasi spesies parasitoid, Bapak Sriyanto Haryanto yang telah membantu memelihara inang parasitoid, Andreas Hendracipta dan Subiadi yang telah membantu dalam pemerangkapan parasitoid di lapangan.

\section{DAFTAR PUSTAKA}

Atmadja WR. 1997. Pembiakan Anagrus sp. dan Oligosita sp., parasitoid telur wereng batang coklat. Di dalam: Arifin, M. et al. (Ed), Prosiding Seminar Nasional PEI. Tantangan Entomologi pada Abad XXI. (Bogor, 8 Januari 1997). pp. 55-61 Bogor: PEI Cabang Bogor.

Atmadja WR. Arifin K. 1990. Parasitasi Anagrus sp., Gonatocerus spp. terhadap beberapa jenis serangga inang pada pertanaman padi. Di dalam: Seminar Hasil Penelitian Tanaman Pangan Bogor (Bogor, 21-22 Februari 1990). pp. 427431. Bogor: Balitan.

Chambers DL. 1977. Quality control in mass rearing. Annual Review Entomology 22:289-308. http:// dx.doi.org/10.1146/annurev.en.22.010177.001445.

Chandra G, Dyck VA. 1988. New techniques of rearing Anagrus flaveolus (Hymenoptera: Mymaridae), an egg parasitoid of the brown planthopper. Entomophaga 33:239-243. http:// dx.doi.org/10.1007/BF02372659.

Chiappini E, Dindo ML, Negri I, Sighinolfi L. 2004. In vitro rearing of Anagrus breviphragma (Hymenoptera: Mymaridae), an egg parasitoid of Cicadella viridis (Hemiptera: Cicadellidae), from second instar larva to adult on diets without insect components. European Journal Entomology 101:419-422.

Darrouzet EL, Bignon C, Chevrier. 2007. Impact of mating status on egg-laying and superparasitism behaviour in a parasitoid wasp. Entomologia Experimentalis et Applicata 123:279-285. http:// dx.doi.org/10.1111/j.1570-7458.2007.00544.x.

Darrouzet E. Boivin G. Chevrier C. 2008. Sex allocation decision under superparasitism by the parasitoid wasp Eupelmus vuilleti. Journal of Insect Behaviour 21:181-191. http://dx.doi. org/10.1007/s10905-008-9118-3.

Gauthier N, Monge JP, Huignard J. 1996. Superparasitisme and host discrinination in the solitary ectoparasitoid Dinarmus basalis. Entomologia Experimentalis et Applicata 79:91-99. http:// dx.doi.org/10.1111/j.1570-7458.1996.tb00813.x.

Kartohardjono A. 2011. Penggunaan musuh alami sebagai komponen pengendalian hama padi berbasis ekologi. Pengembangan Inovasi Pertanian 4:29-46.

Krugner R, Johnson MW, Groves RL, Morse JG. 2008. Host specificity of Anagrus epos: a potential biological control agent of Homalodisca vitripennis. BioControl 53:439-449. http:// dx.doi.org/10.1007/s10526-007-9080-6.

Krugner R, Johnson MW, Morgan DJW, Morse JG. 2009. Production of Anagrus epos Girault (Hymenoptera: Mymaridae) on Homalodisca vitripennis (Germar) (Hemiptera: Cicadellidae) 
eggs. Biological Control 51:122-129. http:// dx.doi.org/10.1016/j.biocontrol.2009.06.013.

Laba IW, Nurbaeti B, Kilin D. 1999. Metode perbanyakan parasioid telur penggerek batang padi putih Scirpophaga innotata (Walker). Di dalam: Prasadja I, Arifin M, Trisawa IM, Laba, IW, Wikardi EA, Soetopo D, Wiratno, Karmawati E. (Ed.), Prosiding Seminar Nasional PEI. Peranan Entomologi dalam Pengendalian Hama yang Ramah Lingkungan dan Ekonomis (Bogor, 16 Februari 1999). pp. 101-115. Bogor: PEI Cabang Bogor.

Maryana N. 1994. Iventarisasi parasitoid telur wereng hijau Nephotettix virescens (Distant) dan wereng coklat Nillaparvata lugens (Stal.) di daerah Bogor dan Cianjur serta pengamatan biologi Gonatocerus sp. Tesis. Bogor: Institut Pertanian Bogor.

Parra JRP. 2010. Mass rearing of egg parasitoids for biological control programs. In: F.L. Consoli et al. (Eds.), Egg Parasitoids in Agroecosystem with Emphasis on Trichogramma. pp. 267-292. Springer Science+ Bussines Media B.V.

Ratna Y. 2011. Mekanisme resurjensi wereng batang padi cokelat setelah aplikasi Deltametrin konsentrasi subletal. Disertasi. Yogyakarta:
Program Pascasarjana, Fakultas Pertanian, Universitas Gadjah Mada.

Santolamazza-Carbone S. Rivera AC. 2003. Superparasitism and sex ratio adjusment in a wasp parasitoid: result at variance with local mate competition. Oecologia 136:365-373. http:// dx.doi.org/10.1007/s00442-003-1269-5.

Trisyono YA. 1991. Efek insektisida buprofezin terhadap parasittelur wereng coklat. Yogyakarta: Laporan Penelitian. Fakultas Pertanian Universitas Gadjah Mada.

Untung K. 2006. Pengantar pengelolaan hama terpadu. Yogyakarta: Gadjah Mada University Press.

Van Lanteren JC, Bakker K, van Alphen JJM. 1978. How to analyse host discrimination. Ecological Entomology 3:71-75.

Yaherwandi, Syam U. 2007. Keanekaragaman dan biologi reproduksi parasitoid wereng coklat Nilaparvata lugens Stal. (Homoptera: Delphacidae) pada struktur lanskap pertanian berbeda. Jurnal Akta Agrosia 10:76-86. http://dx.doi.org/10.1111/j.1365-2311.1978. tb00904.x. 